\title{
A Study of the Reliability and Validity of Holland's RIASEC of Vocational Personalities in Arabic
}

\author{
Nahla Aljojo ${ }^{1, *}$, Huda Saifuddin ${ }^{2}$ \\ ${ }^{1}$ Faculty of Computing and Information Technology, Information Systems Department, King Abdulaziz University, Jeddah, \\ Saudi Arabia \\ ${ }^{2}$ Faculty of Arts and Humanities, Cognitive Psychology Department, King Abdulaziz University, Jeddah, Saudi Arabia \\ *Corresponding author: naljojo@kau.edu.sa
}

\begin{abstract}
There certain problems appear when using English language versions of robust psychometric instruments to identify when it comes to pinpointing Vocational Personalities, in a learning environment other than English native are usually written in English, intended to be used in a Western environment. When employed in a separate language environment, there are problems during translation, as well as cultural matters. An example of this is seen where there are linguistic inconsistencies during literal question or other item translation, meaning there are minor (or major) changes in the meaning for the translates output, which alters the validity and reliability of measurement of the estimations. A word for word translation of Holland's RIASEC of Vocational Personalities was applied to 178 students at the King Abdulaziz University; this is a study that describes validity, internal reliability, factor structure and Correlation Analysis for Holland's RIASEC in Arabic.
\end{abstract}

Keywords: Holland's RIASEC types, vocational interests, personality, reliability, validity, factor analysis, Correlation Analysis

Cite This Article: Nahla Aljojo, and Huda Saifuddin, “A Study of the Reliability and Validity of Holland's RIASEC of Vocational Personalities in Arabic." American Journal of Information Systems, vol. 5, no. 1 (2017): 33-37. doi: 10.12691/ajis-5-1-5.

\section{Introduction}

\subsection{Holland's Theory of Interests}

Holland's [1,2] interest-based theory is split through a total of six personality types and six parallel environments: Realistic (R), Investigative (I), Artistic (A), Social (S), Enterprising (E), and Conventional (C)-referred to collectively as RIASEC. In the Holland model, the connection that exists amongst a human's personality and the environment they find themselves is direct: Personality is defined with regards to a person's opinions regarding work, while work environments are defined with regards to the people who are employed their and the actions they undertake. The RIASEC personality types are described through likes and dislike that affect work environments decisions, and the latter is described through common work actions and various requirements of employees. Under Holland's [1,2] theory, the six RIASEC categories are defined based on a circular ordering, with the differences amongst these being inversely proportional to how similar they are (see Figure 1).

Holland described this framework as a hexagon, but numerous other researchers have described the circular ordering and structure of the six RIASEC categories as a circumplex $[3,5,6]$. In most cases, research has put forward the notion that the six RIASEC interest types and work environments in the United States are, in fact, of a circular ordering [5,6]. As a result, Holland's categorisation of interest types and parallel environments offers a collection of empirically supported reference points for describing the circumplex framework of interests.

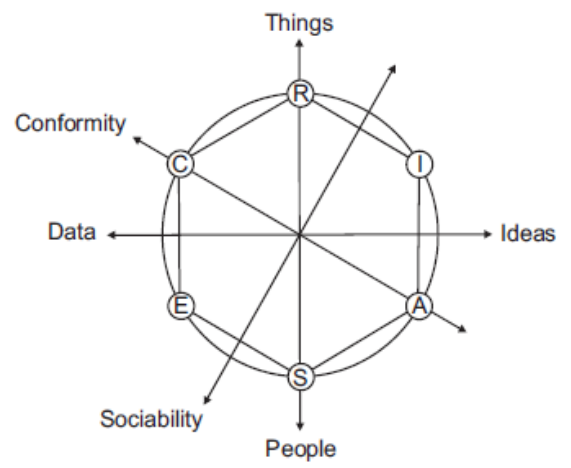

Figure 1. Holland's hexagon, a circumplex model of interest structure with dimensions proposed by Hogan [3] and Prediger [7]

In Holland's RIASEC of Vocational Personalities (Arabic version), there are 106 questions, with every one needing the reader to respond with yes or no, and 18 questions can under each of the six personality types Realistic (R), Investigative (I), Artistic (A), Social (S), and Enterprising (E). The exception is with conventional $(\mathrm{C})$, being involved in sixteen questions. The questions are shown, split up, in Table 1 below. When displaying these queries to students, there were only yes or no answers provided for each question [8]. 
Table 1. The Questions of RIASEC

\begin{tabular}{|c|c|c|c|c|c|c|c|c|c|c|c|c|c|}
\hline \multirow{2}{*}{$\mathrm{R}$} & 3 & 8 & 10 & 15 & 26 & 31 & 36 & 37 & 42 & 45 & 54 & 65 & 82 \\
\hline & 85 & 96 & 99 & 100 & 101 & & & & & & & & \\
\hline \multirow{2}{*}{ I } & 13 & 16 & 18 & 19 & 25 & 29 & 43 & 44 & 48 & 50 & 52 & 60 & 66 \\
\hline & 73 & 76 & 77 & 93 & 98 & & & & & & & & \\
\hline \multirow{2}{*}{ A } & 1 & 4 & 14 & 17 & 32 & 33 & 35 & 40 & 47 & 49 & 58 & 68 & 80 \\
\hline & 81 & 90 & 91 & 102 & 105 & & & & & & & & \\
\hline \multirow{2}{*}{$\mathrm{S}$} & 5 & 6 & 7 & 22 & 23 & 28 & 46 & 59 & 62 & 63 & 64 & 67 & 72 \\
\hline & 78 & 84 & 88 & 94 & 104 & & & & & & & & \\
\hline \multirow{2}{*}{ E } & 9 & 11 & 20 & 21 & 30 & 34 & 41 & 51 & 53 & 55 & 61 & 69 & 74 \\
\hline & 75 & 89 & 95 & 97 & 106 & & & & & & & & \\
\hline \multirow{2}{*}{$\mathrm{C}$} & 2 & 12 & 24 & 27 & 38 & 39 & 56 & 57 & 70 & 71 & 79 & 83 & 86 \\
\hline & 87 & 92 & 103 & & & & & & & & & & \\
\hline
\end{tabular}

\subsection{Reliability and Validity}

Measures of reliability are employed in order to establish how consistent test scores are, and the degree to which the test results are impacted by external factors. When test reliability is greater, then there is a larger chance of there being consistency when evaluating differences amongst individuals. How reliable a tool is can be shown through correlation coefficients. A reliability coefficient is described with the letter $r$, and is a number between 0.00 and 1.00 , where $r=0$ denotes zero reliability, and $\mathrm{r}=1.00$ denoting perfect reliability. Crucially, it should be highlighted that tests are not completely reliable, so $\mathrm{r}=1.00$ is an impossible score to achieve. In all cases, reliability coefficients are shown as a decimal, and when this is larger, then the test scores are considered to be more reliable and consistent [9].

Validity is the second most crucial element when testing and making the decision to employ an assessment tool. Reliability concentrates of the consistency of the evaluation outcomes, whereas validity assesses usefulness. In order for a test to be considered valid, it needs to offer data that is beneficial when it comes to making decisions. Validity evidence states that conclusions and predictions are categorised through the test results.

Certain types of evidence are able to offer data based on the valid use of a test. All evidence is able to establish the level of usefulness the test will have with specific individuals and situations. It is usually the case that various validity types are examined in detail (e.g. construct validity, content validity, criterion validity), it is better to consider these as sources of evidence that assess the overall validity of the test [9].

Face validity is how much a measure is seen to be linked with a certain construct, from the perspective of the target group that the test is applied to [10]. In most cases, respondents of a scale offer feedback on scale items based on if they offer a robust and detailed depiction of the main idea. Face validity of the short version of RIASEC was appraised by fifty five females aged twenty to twenty-four years old. These individuals were all students at the King Abdul-Aziz University (Faculty of Computing and Information Technology), where twenty-eight were studying computer science majors and twenty-seven were studying information system majors. The feedback received showed that the shorter version of RIASEC needed greater support on certain items.

As with face validity, content validity is related to the level that a scale accurately depicts the proposed construct [10]. On the other hand, instead of using the general public, experts evaluate their specialist subject area. These experts offer feedback on the meaning of scale items, and whether they are connected to the key concept accurately, as well as the construct of the general scale.

In this study, content validity has been evaluated by seven psychologist experts. According to these experts, the original RIASEC scale is widely used in Saudi Arabia for career planning, and provides correct guidance for an individual's career development. Psychological Counselor experts state that job interests are the best point from which to start when determining the right career path for a person.

\section{Literature Review}

Holland's typology received worldwide acclaim because of how straightforward it is, its ability to be empirically evaluated, its ease of use, and how easily understood the results are [11]. One of the most appropriate instruments suggested for evaluation with the RIASEC types is the Self-Direct-Search - SDS [12]. It has undergone 25 various translations, employed by over 22 million individuals from across the global, with a mixture of cultural backgrounds [13]. The main ideas in place regarding the six types of vocational personality have wider empirical support, with outcomes stemming from numerous cross-cultural and meta-analytical papers underline the associated validity $[2,14,15,16,17,19]$.

Under the Brazilian environment, the outcomes of the empirical studies through the Questionário de Busca Auto-Dirigida [20], the title offered to the commercial side of Brazil's SDS, are in line with other worldwide results. For example, Mansão and Yoshida [21], present clear findings for the validity linked to the SDS's internal structure. Further research employing SDS uncovered evidence for validity through the RIASEC model in Brazil, and in particular as it is connected with 
external variables, critical for the comprehension of certain career types, like personality $[22,23,24]$; career choice [4,5]; other measures of interest [20,23]; self-efficacy for occupational activities [22]; cognitive skills [22,23]; sex, school year [4] and parents' education [25].

It has been stated in the work of Goldberg [26] that there are issues surrounding copyright restrictions in personality testing. On a different note, Holland [2] has put forward the notion that the completion of the RIASEC scale is thought of as an intervention linked independently with a career, because of the number of job opportunities being given to the participants [27]. Certain individuals might have a propensity to enjoy many of the items on the scale, due to their psychological disposition. Conversely, it can also be the scale that a critical personality might make them lean towards a stronger dislike for the scale's items, or a general negative attitude towards them [18]. In addition, RIASEC scales can be confused with matters of prestige and gender [28]. Situational factors' effect on how personalities are shared can also have missing areas. Tett and Burnett [29] underline the fact that there are specific situational factors that impact trait expression which can be employed to underline the conditions which prefer personality use in selection efforts.

A Turkish research paper used a RIASEC scale made up of 41 items and changed to fit Turkish language and culture. Every RIASEC type was depicted through 6 or 7 items. The results were gathered from a sample of 364 business professionals. Survey outcomes showed that there was a satisfactory level of reliability for the scale, with a Cronbach's alpha of 0.889 .

The paper's results put forward the notion that a short version of RIASEC requires significant changes in order to provide validity when it comes to vocational profiling in the Turkish environment. Out of the potential alterations shown in earlier comments, there must be extra attention given in order to not cause problems when choosing Realistic and Conventional; Enterprising and Recognition items. Moreover, Social and Conventional dimensions of RIASEC are shown to be linked with Work Values, and so reviewing the items with these limitations in mind can be of greater relevance to interests, compared to values that will significantly boost discriminant validity [30].

\section{Methodology and Results}

The robust Arabic translation consisted of a process involving a literal translation from English to Arabic, then back from Arabic to English using different Arabic language experts. Then, a group of 7 Arabic and English speaking psychologists and language experts were used to ensure consistency of meaning and concepts covering each of the 106 questions in the Arabic version of Holland's RIASEC. The Arabic version of Holland's RIASEC was applied to a selection 178 females students. All participants were students from the King Abdul-Aziz University (Faculty of Computing and Information Technology), with twenty-eight of them studying computer science majors, twenty-seven studying information system majors, and one hundred and twenty three being preparatory year distance learning students.

\subsection{Internal Consistency Reliability}

To estimate the internal consistency reliability of the scores, the Cronbach's alpha coefficient was calculated for each of the six Vocational Personalities of the Arabic version of Holland's RIASEC, based on the sample of 178 female students. All participants were students from the King Abdul-Aziz University (Faculty of Computing and Information Technology), with twenty-eight of them studying computer science majors, twenty-seven studying information system majors, and one hundred and twenty three being preparatory year distance learning students. The value of Cronbach's alpha is represented in Table 2.

Table 2. The value of Cronbach's alpha

\begin{tabular}{|c|c|}
\hline RIASEC & Cronbach's alpha \\
\hline Realistic (R) & .601 \\
\hline Investigative (I) & .628 \\
\hline Artistic (A) & .621 \\
\hline Social (S) & .600 \\
\hline Enterprising (E) & .699 \\
\hline Conventional (C) & .669 \\
\hline
\end{tabular}

\subsection{Comparison of the Arabic Version of Holland's RIASEC Scores between Computer Science Majors, Information System Majors, and Preparatory Year Distance Learning Students}

The comparison of students with computer science majors, information system majors, and preparatory year distance learning student's results from the Arabic version of Holland's RIASEC survey are shown in Table 3, based on Vocational Personalities frequencies as follows:

- High Vocational Personalities of student Computer science as Social (S), while there are low Vocational Personalities as Artistic (A).

- High Vocational Personalities of student Information system as Artistic (A), while there are low Vocational Personalities as Realistic (R).

- High Vocational Personalities of student Preparatory year distance learning as Social (S), while there are low Vocational Personalities as Realistic (R).

\subsection{Factors Analysis}

Factor analysis provides evidence of construct validity for the Arabic version of Holland's RIASEC. As a final verification of the items' ability to represent the Holland interest areas appropriately, 106 items were subjected to factor analysis. A principal component analysis with a sixfactor solution was rotated using a varimax procedure. Table 4 shows the rotated factor loadings for each item on each scale. 
Table 3. Comparison of student's Vocational Personalities frequencies

\begin{tabular}{|c|c|c|c|c|c|c|}
\hline Majors & Realistic (R) & Investigative (I) & Artistic (A) & Social (S) & Enterprising (E) & Conventional (C) \\
\hline Computer science & $61 \%$ & $63 \%$ & $58 \%$ & $71 \%$ & $61 \%$ & $62 \%$ \\
\hline Information system & $64 \%$ & $65 \%$ & $80 \%$ & $76 \%$ & $68 \%$ & $73 \%$ \\
\hline $\begin{array}{c}\text { Preparatory year } \\
\text { distance learning }\end{array}$ & $56 \%$ & $63 \%$ & $70 \%$ & $74 \%$ & $66 \%$ & $61 \%$ \\
\hline
\end{tabular}

Table 4. Principal Component Analysis.

\begin{tabular}{|c|c|c|c|c|c|c|c|c|c|c|c|}
\hline \multicolumn{2}{|c|}{ Realistic } & \multicolumn{2}{|c|}{ Investigative } & \multicolumn{2}{|c|}{ Artistic } & \multicolumn{2}{|c|}{ Social } & \multicolumn{2}{|c|}{ Enterprising } & \multicolumn{2}{|c|}{ Conventional } \\
\hline Item & Load & Item & Load & Item & Load & Item & Load & Item & Load & Item & Load \\
\hline q3_R & .519 & q13_I & .698 & q1_A & .655 & q5_S & .648 & q9_E & .443 & q2_C & .426 \\
\hline q8_R & .537 & q16_I & .606 & q4_A & .725 & q6_S & .611 & q11_E & .523 & q12_C & .494 \\
\hline $\mathrm{q} 10 \mathrm{R}$ & .762 & q18 I & .603 & q14 A & .652 & q7 $\mathrm{s}$ & .574 & $\mathrm{q} 20 \mathrm{E}$ & .644 & $\mathrm{q} 27 \mathrm{C}$ & .651 \\
\hline q15_R & .591 & q19_I & .672 & q17_A & .735 & q22_S & .668 & q21_E & .518 & q38_C & .332 \\
\hline q26_R & .573 & q25_I & .505 & q32_A & 609 & q23_S & .541 & q30_E & .571 & q39_C & .474 \\
\hline q31_R & .642 & q29_I & .460 & q33_A & .581 & q28_S & .566 & q34_E & .518 & q92_C & .587 \\
\hline q36_R & .608 & q43_I & .498 & q35_A & .593 & q46_S & .499 & q41_E & .582 & q103_C & .399 \\
\hline q37_R & .663 & q44_I & .462 & q40_A & .659 & q59_S & .561 & q51_E & .575 & q24_C & .520 \\
\hline q42_R & .540 & q48_I & .720 & q47_A & .434 & q62_S & .565 & q53_E & .568 & q56_C & .607 \\
\hline q45_R & .591 & q50_I & .621 & q49_A & .635 & q63_S & .670 & q55_E & .606 & q57_C & .563 \\
\hline q54_R & .567 & q52_I & .539 & q58_A & .615 & q64_S & .669 & q61_E & .507 & q86_C & .591 \\
\hline q65_R & .768 & q60_I & .578 & q68_A & .690 & q67_S & .515 & q69_E & .487 & q87_C & .568 \\
\hline q82_R & .813 & q66_I & .709 & q80_A & .728 & q72_S & .488 & q74_E & .667 & q70_C & .623 \\
\hline q85_R & .558 & q73_I & .478 & q81_A & .723 & q78_S & .488 & q75_E & .467 & q71_C & .512 \\
\hline q96_R & .484 & q76_I & .445 & q90_A & .563 & q84_S & .666 & q89_E & .520 & q79_C & .553 \\
\hline q99_R & .697 & q77_I & .485 & q91_A & .643 & q88_S & .503 & q95_E & .516 & q83_C & .442 \\
\hline q100_R & .721 & q93_I & .551 & q102_A & .720 & q94_S & .582 & q97_E & .442 & & \\
\hline q101_R & .590 & q98_I & .617 & q105_A & .695 & q104_S & .564 & q106_E & .636 & & \\
\hline
\end{tabular}

\subsection{Correlation Analysis}

As seen in Table 6, inter-correlations among Holland's Vocational Personalities are as follows [8]:

- Realistic which correlated positively with Artistic, Social, Enterprising, Conventional, and Investigative

- Artistic which correlated positively with Realistic, Conventional, Social, Enterprising and Investigative

- Conventional which correlated positively with Artistic, Social, Enterprising, Realistic and Investigative

- Social which correlated positively with Realistic, Artistic, Conventional, Enterprising and Investigative

- Enterprising which correlated positively with Realistic, Artistic, Conventional, Social and Investigative
- Investigative which correlated positively with Realistic, Artistic, Conventional, Social and Enterprising.

Table 5. Descriptive Statistics

\begin{tabular}{|c|c|c|c|}
\hline & Mean & Std. Deviation & N \\
\hline R & 10.4551 & 2.71024 & 178 \\
\hline A & 11.3820 & 2.83045 & 178 \\
\hline C & 11.2640 & 2.72319 & 178 \\
\hline S & 13.3202 & 2.65401 & 178 \\
\hline E & 11.8202 & 3.18209 & 178 \\
\hline I & 11.3146 & 2.99753 & 178 \\
\hline
\end{tabular}

Table 6. Correlations Matrix

\begin{tabular}{|c|c|c|c|c|c|c|c|}
\hline & & $\mathrm{R}$ & A & $\mathrm{C}$ & $\mathrm{S}$ & $\mathrm{E}$ & I \\
\hline \multirow{3}{*}{$\mathrm{R}$} & Pearson Correlation & 1 & $.474^{* *}$ & $.310^{* *}$ & $.412^{* *}$ & $.378^{* *}$ & $.486^{* *}$ \\
\hline & Sig. (2-tailed) & & .000 & .000 & .000 & .000 & .000 \\
\hline & $\mathrm{N}$ & 178 & 178 & 178 & 178 & 178 & 178 \\
\hline \multirow{3}{*}{ A } & Pearson Correlation & $.474^{* *}$ & 1 & $.273^{* *}$ & $.482^{* *}$ & $.486^{* *}$ & $.448^{* *}$ \\
\hline & Sig. (2-tailed) & .000 & & .000 & .000 & .000 & .000 \\
\hline & $\mathrm{N}$ & 178 & 178 & 178 & 178 & 178 & 178 \\
\hline \multirow{3}{*}{$\mathrm{C}$} & Pearson Correlation & $.310^{* *}$ & $.273^{* *}$ & 1 & $.564^{* *}$ & $.567^{* *}$ & $.586^{* *}$ \\
\hline & Sig. (2-tailed) & .000 & .000 & & .000 & .000 & .000 \\
\hline & $\mathrm{N}$ & 178 & 178 & 178 & 178 & 178 & 178 \\
\hline \multirow{3}{*}{$\mathrm{S}$} & Pearson Correlation & $.412^{* *}$ & $.482^{* *}$ & $.564^{* *}$ & 1 & $.686^{* *}$ & $.536^{* *}$ \\
\hline & Sig. (2-tailed) & .000 & .000 & .000 & & .000 & .000 \\
\hline & $\mathrm{N}$ & 178 & 178 & 178 & 178 & 178 & 178 \\
\hline \multirow{3}{*}{ E } & Pearson Correlation & $.378^{* *}$ & $.486^{* *}$ & $.567^{* *}$ & $.686^{* *}$ & 1 & $.565^{* *}$ \\
\hline & Sig. (2-tailed) & .000 & .000 & .000 & .000 & & .000 \\
\hline & $\mathrm{N}$ & 178 & 178 & 178 & 178 & 178 & 178 \\
\hline \multirow{3}{*}{ I } & Pearson Correlation & $.486^{* *}$ & $.448^{* *}$ & $.586^{* *}$ & $.536^{* *}$ & $.565^{* *}$ & 1 \\
\hline & Sig. (2-tailed) & .000 & .000 & .000 & .000 & .000 & \\
\hline & $\mathrm{N}$ & 178 & 178 & 178 & 178 & 178 & 178 \\
\hline
\end{tabular}




\section{Discussion \& Conclusion}

A key outcome of this paper is that the use of the translated Arabic version of Holland's RIASEC of Vocational Personalities shows internal consistency. As a result, there is evidence supporting the use of the Arabic version of Holland's RIASEC of Vocational Personalities as a metric for gathering and comprehending Vocational Personalities of Arabic speaking learners.

This study looks at how reliable and valid findings from Holland's RIASEC of Vocational Personalities were. Reliability investigates how consistent the evaluation was, whereas validity is focused on the conclusions drawn from the test results. To accurately evaluate psychological traits to maximise the usefulness, there must be sufficient reliability and validity. The reliability prediction for the six Vocational Personalities of the Arabic version of Holland's RIASEC using 178 students in the Arabic translation showed that the value of Cronbach's alpha was substantial, between 0.601 and 0.699.

Factor analysis of the Holland's RIASEC identified six factors related to the six Vocational Personalities. An examination of the construct involved, together with psychologist expert discussion for every facto, showed that the variables had a clear relation to the goals of the item, offering input regarding construct validity for Holland's RIASEC, as well as inter-correlations between Holland's Vocational Personalities being shown to have a positive correlation.

\section{References}

[1] Holland, J. L. (1959). A theory of vocational choice. Journal of counseling psychology, 6(1), 35 .

[2] Holland, J. L. (1997). Making vocational choices: A theory of vocational personalities and work environments. Psychological Assessment Resources.

[3] Hogan, R. (1983). A socioanalytic theory of personality. In M. M. Page (Ed.), Nebraska Symposium on Motivation: Vol. 30. Personality: Current theory and research (pp. 55-89). Lincoln: University of Nebraska Press.

[4] Sartori FA, Noronha APP, Godoy S, \& Ambiel RAM. (2010). Interesses profissionais de jovens de ensino médio: Estudo correlacional entre a Escala de Aconselhamento Profissional e o Self-Directed-Search Carrier Explorer ENT\#091;Professional interests of high school students: A correlational study between the Escala de Aconselhamento and Self-Directed-Search Career ExplorerENT\#093;. Estudos de Psicologia (Campinas), 27(2), 215-225.

[5] Rounds, J., \& Tracey, T. J. (1993). Prediger's dimensional representation of Holland's RIASEC circumplex. Journal of Applied Psychology, 78, 875-890.

[6] Rounds, J., Tracey, T. J., \& Hubert, L. (1992). Methods for evaluating vocational interest structural hypotheses. Journal of Vocational Behavior, 40, 239-259.

[7] Prediger, D. J. (1982). Dimensions underlying Holland's hexagon: Missing link between interests and occupations? Journal of Vocational Behavior, 21, 259-287.

[8] Aljojo, N. (2016). Choosing a Career Based Personality Matching: A Case Study of King Abdulaziz University. INTERNATIONAL JOURNAL OF ADVANCED COMPUTER SCIENCE AND APPLICATIONS, 7(2), 215-221.

[9] Bakker, S., \& Macnab, D. (2004). Career Interest Profiler Manual.

[10] Furr, R. M., Scale construction and psychometrics for social and personality psychology, London: SAGE Publications, (2011).
[11] Nauta MM. (2010). The development, evolution, and status of Holland's theory of vocational personalities: Reflections and future directions of counseling psychology. Journal of Counseling Psychology, 57(1), 11-22.

[12] Holland JL, Fritzsche B, Powell A. (1994). SDS Self-DirectedSearch: Technical manual. Odessa, FL: Psychological Assessment Resources.

[13] Goldstein G, Hersen M. (2000). Handbook of psychological assessment (3rd ed.). Oxford, United Kingdom: Elsevier Science.

[14] Kantamneni N, Fouad N. (2011). Structure of vocational interests for diverse groups on the 2005 strong interest inventory. Journal of Vocational Behavior, 78(2), 193-201.

[15] Rounds J, Tracey TJ. (1996). Cross-cultural structural equivalence of RIASEC models and measures. Journal of Counseling Psychology, 43(3), 310-329.

[16] Tien H-LS. (2011). An exploration of adult career interests and work values in Taiwan. Asia Pacific Education Review, 12(4), 559-568.

[17] Tracey, T. J., \& Rounds, J. (1992). Evaluating the RIASEC circumplex using high-point codes. Journal of Vocational Behavior, 41, 295-311.

[18] Walsh, W. B., Savickas, M. L., \& Hartung, P. J. (2013). Handbook of Vocational Psychology: Theory, Research, and Practice. Routledge.

[19] Yang W, Stokes GS, Hui CH. (2005). Cross-cultural validation of Holland's interest structure in Chinese population. Journal of Vocational Behavior, 67(3), 379-396.

[20] Primi R, Mansão CSM, Muniz M, Nunes MFO. (2010). SDS Questionário de busca auto-dirigida para psicólogos: Manual técnico da versão brasileira ENT\#091; SDS - Self-Directed-Search Questionnaire for psychologists: Technical manual of the Brazilian versionENT\#093; São Paulo, SP: Casa do Psicólogo.

[21] Mansão CSM, Yoshida EMP. (2006). SDS - Questionário de Busca Auto-Dirigida: Precisão e validade ENT\#091; SDS - SelfDirected Search Career Explorer: Precision and validityENT\#093; Revista Brasileira de Orientação Profissional, 7(2), 67-79. Retrieved from http://pepsic.bvsalud.org/pdf/rbop/v7n2/v7n2a07.pdf

[22] Nunes MFO, Noronha APP. (2009). Relações entre interesses, personalidade e habilidades cognitivas: Um estudo com adolescentes ENT\#091; Relationships between interests, personality and cognitive abilities: A study with adolescentsENT\#093;. Psico-USF, 14(2), 131-141.

[23] Primi R, Bighetti CA, Munhoz AH, Noronha APP, Polydoro SAJ, Di Nucci EP, Pelegrini MCK. (2002). Personalidade, interesses e habilidades: Um estudo correlacional da BPR-5, LIP e do 16PF ENT\#091; Personality, interests and abilities: A correlational study of BPR-5, LIP and 16PFENT\#093;. Avaliação Psicológica, 1(1), 61-72. Retrieved from

http://pepsic.bvsalud.org/pdf/avp/v1n1/v1n1a07.pdf

[24] Primi R, Moggi MA, Casellato EO. (2004). Estudo correlacional do Inventário de Busca Auto-Dirigida (self-directed-search) com o IFP ENT\#091; Correlational study of the Self-Directed Search with the IFPENT\#093;. Psicologia Escolar e Educacional, 8(1), 47-54.

[25] Noronha APP, Ottati F. (2010). Interesses profissionais de jovens e escolaridade dos pais ENT\#091; Youth's professional interests and their parents' educationENT\#093;. Revista Brasileira de Orientação Profissional, 11(1), 37-47. Retrieved from http://pepsic.bvsalud.org/pdf/rbop/v11n1/v11n1a05.pdf

[26] Goldberg, L. R., A broad-bandwidth, public-domain, personality inventory measuring the lower-level facets of several five-factor models, (1999).

[27] Armstrong, P., Allison, W., \& Rounds, J., Development and initial validation of brief public domain RIASEC marker scales. Journal of Vocational Behavior, 73, 287-299, (2008).

[28] Deng, C.P., Armstrong, P. I., \& Rounds, J., The fit of Holland's RIASEC modelto US.

[29] Tett, R. P., \& Burnett, D. D., A Personality Trait-Based Interactionist Model of Job Performance. Journal of Applied Psychology, 2003, Vol. 88, No. 3, 500-517, (2003).

[30] Süerdem, A., \& Erkök, B. (2016, January). Assessing the reliability and validity of a shorter version of RIASEC in Turkish. In SHS Web of Conferences (Vol. 26). EDP Sciences occupations. Journal of Vocational Behavior, 71, 1-22, (2007). 